\title{
Reliability Studies
}

for the

\section{Nuclear-Powered Artificial Heart Program}

by

M. Horita

R. K. Zeigler 
This work was done for the US Energy Research and Development Administration, Division of Biomedical and Emvironmenta! Research.

Printed in the United States of America. Avalable from National Technical Information Service

U.S. Department of Commerce

5285 Port Royal Road

Springfield, VA $2215 \mathrm{I}$

Price: Printed Copy $\$ 3.50$ Microfiche $\$ 2.25$

This report way orepared as an eccount of work sponoored

nor the ('nited Btates Finerzy Reseirch and Development Ad.

miniztration, nor ans of their employers, nor anv of their run.

trartors. aubcontractors. of their employets. makee onj

warraily, express or implied, or anumes any lezal tipbiticy or

responsibility for the accuracv. completeness. or usefulness of

represents that its use would not infricke privetely owned

rights. 


\section{RI:L.ABILJTY STUNTES}

FOR

TII: NUCLLAR-POWLRID ARTIF1C1AL HFART PROCRAM

by

M. Horita and R. K. Zeigler

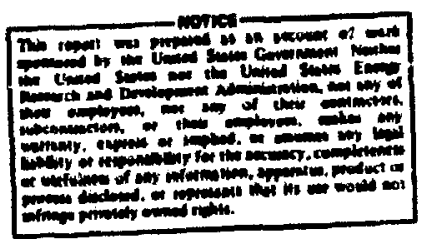

\section{ABSTRACT}

By assuming that the failures of an artificial heart systen with a mean 1 ife of 10 years can be modeled by a particular probability distribution, both the probability of a failure in the system within $t$ years and the reliability required of each subsystem and component are invest igated.

\section{INIRODUCT IOS}

The objective of the Nuclear-Powered Artificial Heart Prototype System nevelopment lrogram being conducted by the Division of biomedical Environmental Research (DBER) of the linerey Research and Development Administration (IRDA) is to develop a fully implantable nuclear-powered artificial heart with a mean life (life expectancy) of $10 \mathrm{yr}$. This report investigates the reliability of such an artificial heart system. Here, reliability is defined as the probability that a device will perform adequately for a specified period after implantation. It also indicates the implications of various assumptions about subsystem or component reliability and the requirements that may be imposed on component structure in light of DBER's objectives.

For simplicity, the heart is treated first as a single basic unit. By assuming that the artificial heart system failures can be modeled by a particular probability distribution, the probability of a failure in the system within $1,2, \ldots$,
15 yr is calculated. In particular, the expozential, normal, lognormal, gamma, and heibull distributions are considered. In reality, however, the artificial heart is composed of 4 subsystems with $53,57,5$, and 4 components, respectirely. Using the probability distributions mentioned previous 1 y and further assuming that the heart is a simple series system each of whose subsystems and components has the same failure distribution, the mean 1 ife required of each subsystem and, subsequently, of each component is cal. culated. In this calculation, however. it is necessary to alter DALR's objective of developing a heart with a mean life of 10 yr by considering a heart with a median life of $10 \mathrm{yr}$ instead. (Discussion of this topic begins on page 10.) Given results whose distribution is unknown, the additional constraint of setting equal to 0.5 the probability that the system's time to failure will be less than or equal to 10 $y r$, i.e., $p(T<10)-0.5$, makes $10 \mathrm{yr}$ the median of the distribution by definition. 
Finally, two ozher approaches to this probiem are considered. If each heart sys. tem component is assumed to have the same failure distribution, the median lifo re. quired of each subsystem with $k_{i}$ components can be calculated. Purther, if each subsystem is assumed to have the same failure distribution, in particular, the same median life, the mean life required of each component of a particular subsystem also can be calculated. These results are tabulated for closer inspection.

This report does not give any final answers about the reliability and mean or median life requirements of the components of a complex artificial heart system like the protetype that DBI:R is developing. It does indiente some possible ap. proaches and their consequences by simplifying the problem tinrough easing consider. ations and calculations.

2. THE IIFART AS A SINCLI: MASJE SYSTEM 2.1. The fxponential Filifure bistribution The exponential distribution it: chosen as the fallure distribution if it can be assumed thas the fajlure rate function is constant, say $A$. This assumption implies a lack-of-memory property or no "aging" effect.

Let $T$ be a random variable that represents system time to failure. The exponenzlal probability density cunction, puf, is

$$
f(t)= \begin{cases}\frac{1}{3} e^{-t / t}, & t=0 \\ 0 & , e I \text { sewhere, }\end{cases}
$$

where $t$ denr:es $t$ ime. The mean, $l(T)$, is $\lambda$ which when set equal to In $\mathrm{yr}$, the mean life of the heart system, implies that the variance is $V(T)=\lambda^{2}=100$. The stand. ard deviation or positive square root of the variance is $S D(T)$ i 10 . To calculate the probahility of a failure in the system within $t$ years, use

$$
P(T<t)=\int_{0}^{t} \frac{1}{x} e^{-x / t} d x-1 \cdot e^{\cdot t / 3}
$$

where $P(T<t)$ often is denoted by $l(t)$. the (cumularive) distrilation functina or cdf. Figures 1.3 are graphs of the sxpo" nential paf, edf, and failure rate func. tion, respectlvely.

The probahititics of: In and t 1,2, ... I5 are sumariacd to four decimal places in Tahlo 1 tat the end of this report). Sote that when t - ir. the probibility of a fatluro in the sys-

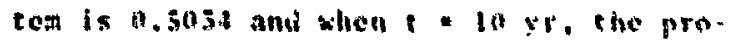
bability is 0.6.32\}. For the prohability of a talure within lo $\mathrm{yr}$ to he shous o.s. a mean ijfe of 14,1 pr is required.

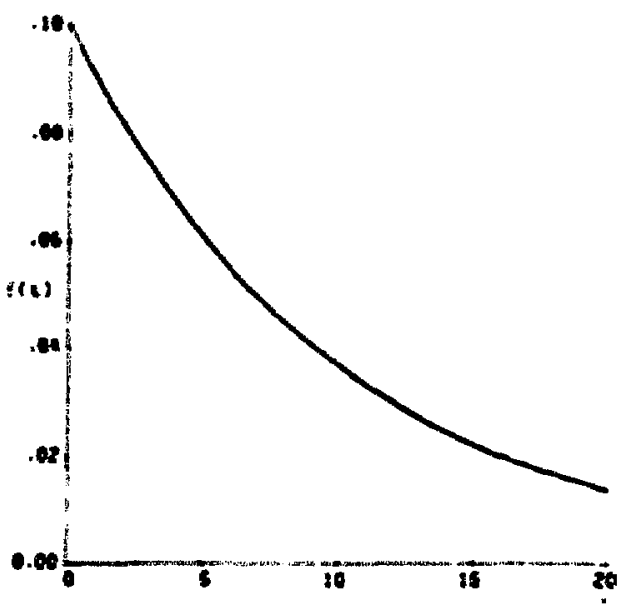

Fig. 1. The exponctitinl probability donsity function with : 10 .

\subsection{The Normal ligilure Distribution}

If the system is subject to aging or gradual failure of its ejectrical or mechanical components, a normal distribution mav be useful in characteri=ing the failure distribution. 


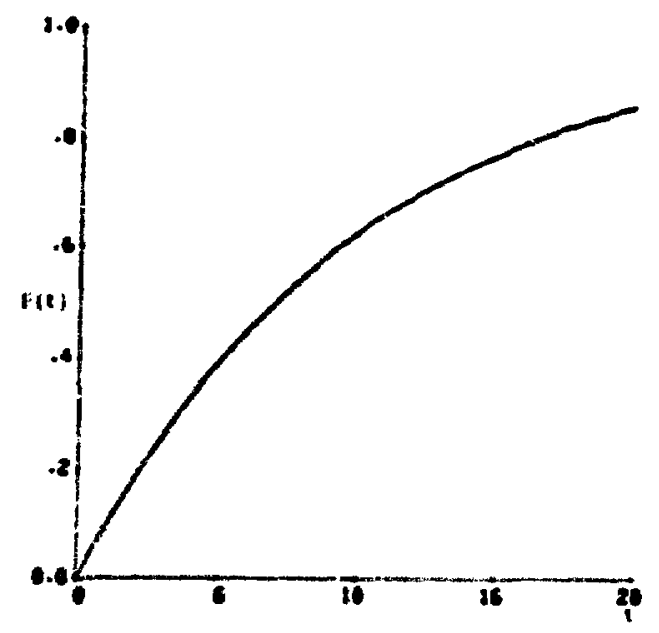

Fit. 2. The exponential cumulative distri. lue ion fanction with $=10$.
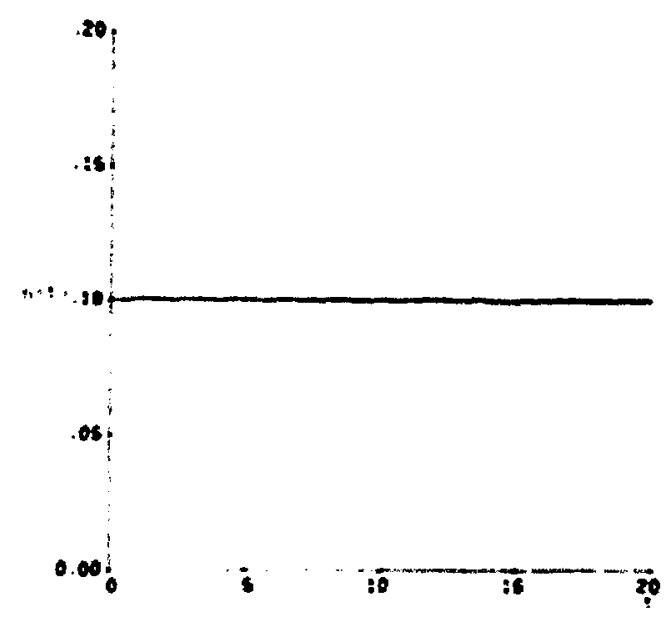

Fis. i. The exponential fallure rate func. tion with $=10$.

The narmal paf is

$r(t) * \frac{1}{20} \exp \left[-\frac{(1-\mu)^{2}}{20^{2}}\right], \cdots \infty t<\infty$ where $u, v^{*}$. ind o are the mean, variance, and stindard deviation, respectively. If a chanpe of variable, $=(t-u) / \sigma$, is used, the probability of a failure in the system within tyears is given by

$$
\begin{aligned}
& P(T \leq t)=P\left(z \leq \frac{t-\mu}{\sigma}\right) \\
& \int_{\infty}^{\frac{t-\mu}{J}} \frac{1}{\sqrt{2 \pi}} e^{-z^{2} / 2} d z=d\left(\frac{t-\mu}{\sigma}\right) .
\end{aligned}
$$

The probabilicies for this standardized normal distribution with mean zero and variance one (standard deviazion one) are conveniently tabulared and available in most statistics texts. " As two parameters, and $\sigma$, are involved, set $u=10$ and select various and arbitrary values of $\sigma$ to investigate the quantity $P(T \leq t)$. Tables tl-ll exhibjt the salculations for $\mu=10$ and $, 1,3,5,7$, and 10 , respectively. The normal par, cdf, and failure rate function for these five sets of parameter valwes are shown in Figs. 4.6 .

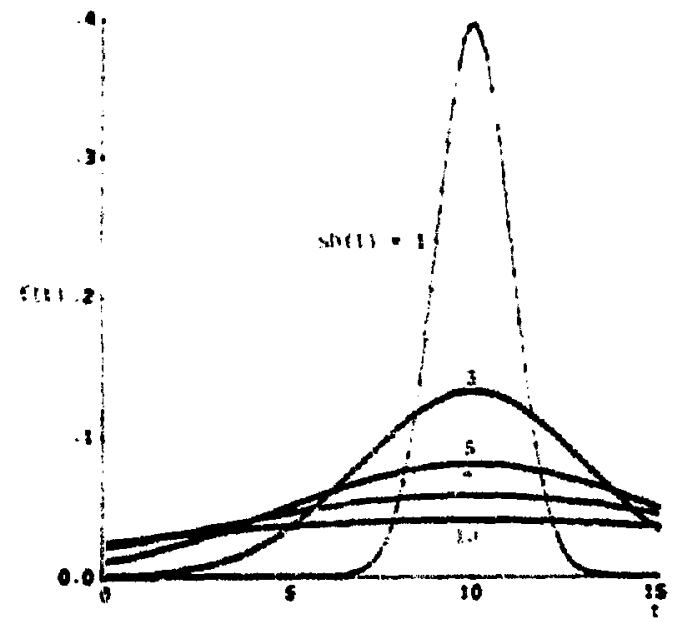

Fig. 4. The normal probabilfty density function with $l(T)-10$ and $\sin (T)=1,3,5, T$, and 10 . 


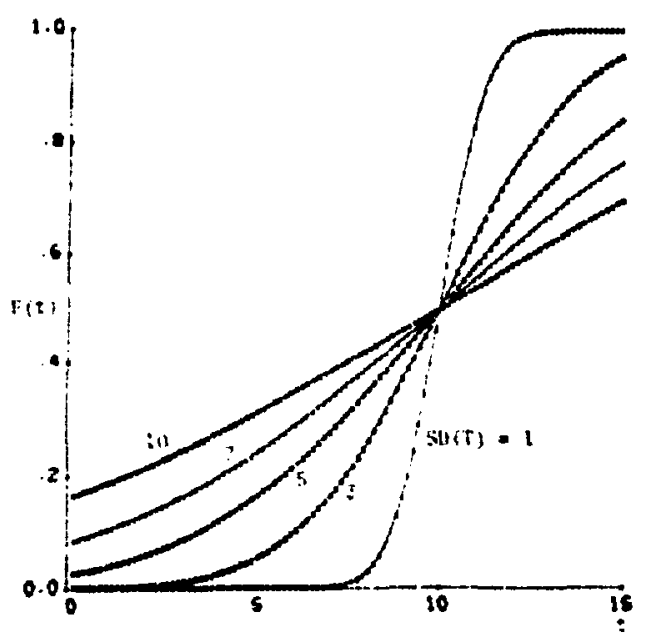

Fig. 5. The normal cumulative distribution function with $E(T)=1 \mathrm{C}$ and $\operatorname{SD}(T)=1,3,5,7$, and 10 .

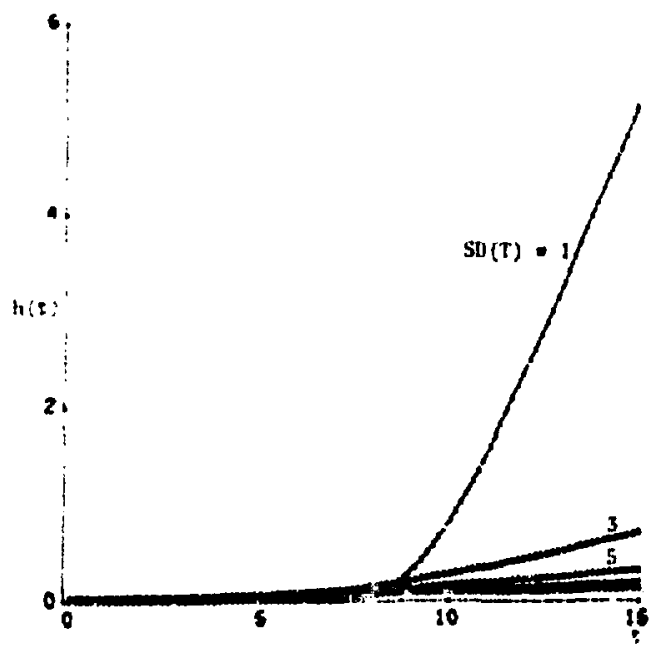

Fig. 0 . The normal failure rate function with $E(T)=10$ and $\operatorname{SD}(T)=1,3$, 5,7 , and 10 .

\subsection{The Lognormal Failure Distribution}

If $X=\log _{e} T$ is normally distributed, $T$ is said to have a lognormal distribution. This distribution has been used to describe the disiribution of nuclear ractor failure rates. The pdf, mean, and variance are

$$
\begin{aligned}
& f(t)= \begin{cases}\frac{1}{t \sqrt{2 \pi} \sigma} \exp \left[-\left(\log _{e}(t)-\mu\right)^{2} /\left(2 \sigma^{2}\right)\right], t>0 \\
0, \text { elsewhere }\end{cases} \\
& E(T)=e^{\mu+\sigma^{2} / 2},
\end{aligned}
$$

and

$$
\begin{aligned}
V(T) & =e^{2 \mu} e^{\sigma^{2}}\left(e^{\sigma^{2}}-1\right) . \\
\text { For } E(T) & =10 \text { and } V(T)=1 \text {, say, } \\
\mu & =E(X)=\log _{e} 10-\sigma^{2} / 2
\end{aligned}
$$

and

$$
\sigma^{2}=V(x)=\log _{e}(1.01) \sim 0.01 .
$$

The standard deviation is $S D(X)-0.10$. By substitution, $\mu=\log _{e} 10 * t .01 / 2 \sim 2.30$. These $\mu$ and $\sigma^{2}$ values can then be used in calculating the probability of a failure in the system within $t$ years, where

$$
\begin{aligned}
& P(T \leq t)=P\left(X \leq \log _{e} t\right)=P\left(z \leq \frac{\log _{e} t-\mu}{\sigma}\right) \\
& =\int_{-\infty}^{\frac{\log _{e} t-\mu}{\sigma}} \frac{1}{\sqrt{2 \pi}} e^{-z^{2} / 2} d z \\
& =\Phi\left(\frac{\log _{e} t \cdot \mu}{\sigma}\right),
\end{aligned}
$$

which is tabulated as previously mentioned. When other values for the standard deviation of $T$ are assigned and calculations similar to those shown above are performed, $F(T)=10$ and $S D(T)=3$ imply that $\mu-2.26$ and $\sigma=0.29 ; E(T)=10$ and $S D(T)=5$ imply 
that $\mu-2.19$ and $\sigma=0.47 ; E(T)=10$ and $\operatorname{SD}(\mathrm{T})=7$ imply that $\mu \sim 2.10$ and $\sigma=0.63$; and $E(T)=10$ and $S l)(T)=10$ imply that $\mu \sim 1.96$ and $\sigma=0.83$. Results are shown in Tables II -VI.

The lognormal pdf, cdf, and failure rate function for the five cases considered above are shown in Figs. 7-9.

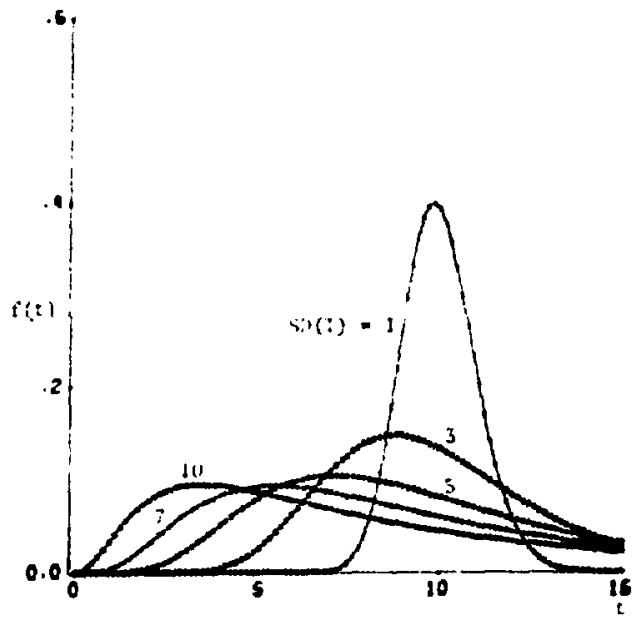

Fig. 7. The lognormal probability density runction with $I:(T)=10$ and $S D(T)=1,3,5,7$, and 10 .

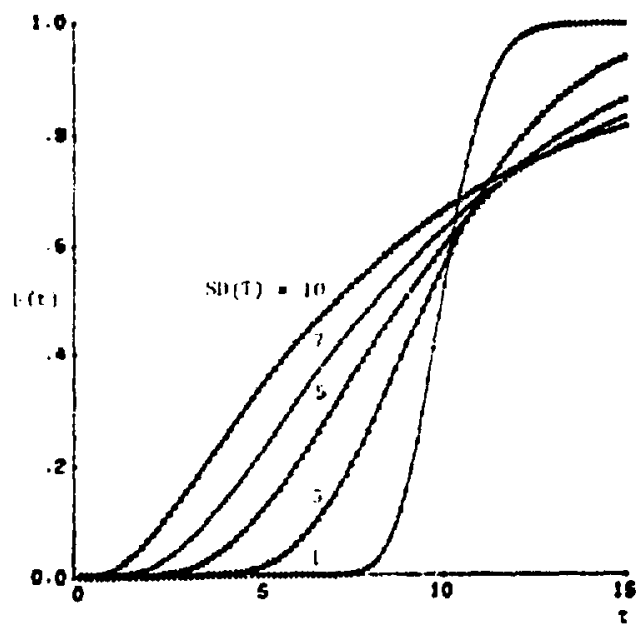

Fig. 8. The iognormal cumulative distribu$t$ ion function with $E(T)=10$ and $\mathrm{SD}(\mathrm{T})=1,3,5,7$, and 10 .

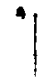

3

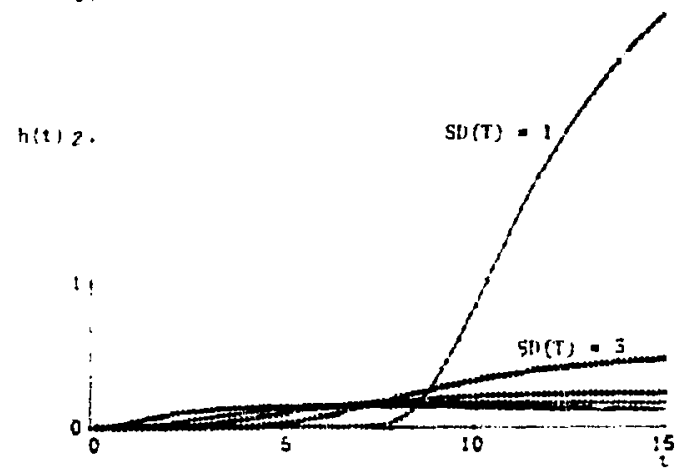

Fig. 9. The lognormal failure rate function with $I:(T)=10$ and $S D(T)=1,3$, 5,7 , and 10 .

\subsection{The Camma Failure Distribution}

The gamma distribution may be useful in characterizing failures if the components in a complex electromechanical system fail instantaneously during the initial (burn-in) stage or the wear-out period of operation.

The gamma pdf, mean, and variance are

$$
\begin{array}{ll}
f(t)= \begin{cases}\frac{1}{\Gamma(\alpha) B^{\alpha}} t^{\alpha-1} e^{-t / B}, & 0<t<\infty \\
0 & , \text { elsewhere, }\end{cases} \\
E(T)=\alpha B . &
\end{array}
$$

and

$$
V(T)=a B^{2}
$$

where $\alpha$ is the shape parameter and $B$ is the scale parameter. Note that when $a=1$, the gamma pdf reduces to the exponential pdf. By graphical depiction, the failure intensity rate increases for $\alpha>1$ and decreases for $\alpha<1$.

The ci,i-square distril-ition is a special case of the gamma distribution with $\alpha=v / 2$ and $B=2$ where $v$ is a positive integer representing the degrees of freedom. 
If $T$ has a gamia distribution with parameters $\alpha$ and $\beta$, then there exists an $X$ such that $T=\frac{\beta X}{2}$ where the random variable $X$ has a chi-square distribution with $v=2 a$ degrees of freedom. Thus, the probability of a failure within $t$ years can be expressed as

$$
n(T \leq t)=P(X \leq 2 t / B)
$$

To calculate that probability, three approximations may be used. 3 The first approximation. standardizes the random variable $X$, that is, subtracts its mean, $v$, and divides by its standard deviation, $\sqrt{2 v}$. As $v+\infty$, the standardized chi-square distribution approaches the standardi:ed normal distribution. Thus.

$$
\begin{aligned}
P(X \leq 2 t / s) & =\Phi\left[\left(\frac{2 t}{s}-v\right)(2 v)^{-1 / 2}\right] \\
& =\Phi\left[\left(\frac{2 t}{B}-2 a\right)(2(2 a))-1 / 2\right] \\
& =\Phi\left(\frac{\frac{t}{B} \cdot a}{\sqrt{a}}\right) .
\end{aligned}
$$

The second approximation is known as Fisher's approximution, and the third is the Wilson-llifferty approximation. Both use approximate standardizaticn and are given as

$$
\begin{aligned}
P(X \leq 2 t / 3)-\sigma & {[\sqrt{2(2 t) 5)}-\sqrt{2(2 a)-1}] } \\
& =\Phi(2 \sqrt{t} \bar{b}-\sqrt{4 a-1})
\end{aligned}
$$$$
P(X \leq 2 t / B)-\left\{\left(\frac{2 t}{B(2 \alpha)}\right)^{1 / 3}-1\right.
$$$$
\left.\left.+\frac{2}{9}(2 \alpha)^{-1}\right] \sqrt{9\left(\frac{2 \alpha}{2}\right)}\right\}
$$$$
=\pi\left\{\left[\left(\frac{t}{\alpha B}\right)^{1 / 3}-1+\frac{1}{9 \alpha}\right] 3 \sqrt{\alpha}\right\} \text {. }
$$

of these three approximations, the first is the least accurate and the third is the most accurate, unless $2 \alpha$ is large, in which case, the difference in accuracy among them is $\operatorname{sma} 11$.

Again, through the arbitrary and consistent assignment of $\mathrm{Sn}(\mathrm{T})=1,3, \mathrm{~S}, 7$, and 10, calculations for these five cases using the Wilson-Hilferty approximation are shown in Talles II-VI, respectively. Setting $E(T)=10$ and $S D(T)=1$ gives $a=100$ and $B=0.10$. Similarly, for $1:(T)=10$ and $S D(T)=3, a-11.11$ and $B=0.90$; for $\mathrm{E}(\mathrm{T})=10$ and $\mathrm{SD}(\mathrm{T})=5, \alpha=4$ and $B=2.50 ;$ for $f(T)=10$ and $S H(T)=7$. $a-2.04$ and $B=4.90$; and for $E(T)=11$ and $S D(T)=10, a=1$ and $\hat{s}=10$.

Figures 10.12 show the gamma pdf, cdf, and failura rate function.

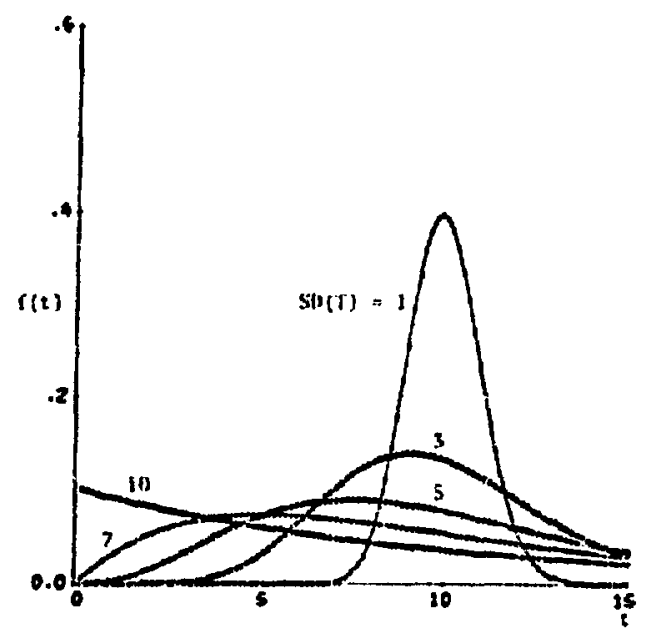

Fig. 10. The gamma probability density function with $F(T)=10$ and $s n(T)=1,3,5,7$, and 10 . 


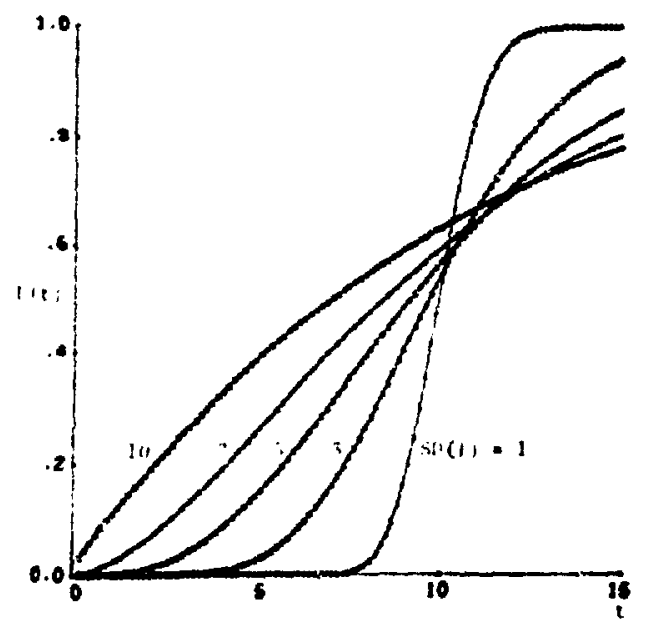

Fig. 11. The gamma cumulative distribu:ion function $w i t h l:(i)=10$ and $\operatorname{SD}(T)=1,3,5,7$, and 10 .

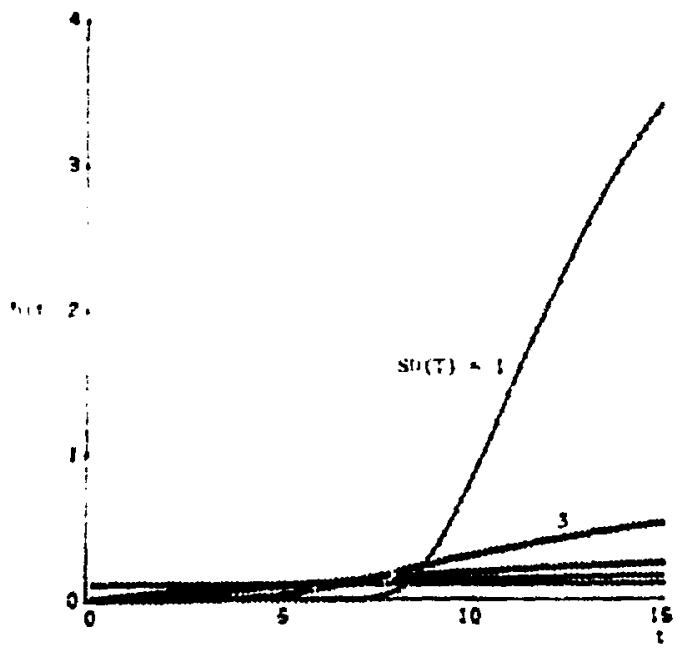

Iig. 12. The gamma failure rate function with $E(T)=10$ and $S D(T)=1,3$. 5,7 , and 10 .

\subsection{The Keibull Failure Distribution}

The Weibull distribution has been useful in accelerated testing of components operating under forced conditions, testing of equipmert such as ball bearings and electron tubes during the initial-failure phase, and in a system involving several components whose failure is attributed to the severest flaw.
The Weibull pdf is

$$
f(t)= \begin{cases}\frac{\gamma}{B} t^{\gamma-1} \exp \left(-\frac{t^{\gamma}}{\beta}\right), & t \geq 0 \\ 0 & , \text { elsewhere, }\end{cases}
$$

where $\gamma$ is the shape parameter and $\&$ is the scale parameter. When $\gamma=1$, the heibuil puf becomes the exponential pdf. An exponential-type graph which can be used to charncterice a decreasing failure intensity rate results when $y<1$. Also, keibull paf's with $\gamma<1$ are useful in describing catastrophic failures. When $\gamma>1$, the graph of the heibull pdf is unimodal. In a more gereral case, wear-out failures and increasing failure intensity rates are best characterized using $\gamma>1$ and $t>a>0$. The mean and variance of the heibull distribution are given by

$$
\begin{aligned}
& E(T)=s^{L / \gamma}[(1+1 / \gamma), \\
& V(T)=e^{2 / \gamma}\left[\Gamma(1+2 / \gamma)-r^{2}(1+1 / \gamma)\right] .
\end{aligned}
$$

To calculate the probability of a failure within $t$ years, the values of $Y$ and $B$ must be determined. For $E(T)=10$ and $V(T)=1$, say,

$$
B^{2 / \gamma}=\frac{100}{\Gamma^{2}(1+1 / \gamma)}
$$

and

$$
\frac{r(1+2 / \gamma)}{r^{2}(1+1 / \gamma)}=1.01
$$

In a trial and error process, $\gamma-12.15$ and $B-2.38 \times 10^{12}$ are a solution to the above equations. In simil r calculations, $E(T)=10$ and $S D(T)=3$ give $\gamma-3.71$ and $B=7.57: 10^{3} ; E(T)=10$ and $\operatorname{SD}(T)=5$ give $\gamma-2.10$ and $B-1.63 \times 10^{2} ; E(T)=10$ and $\mathrm{SD}(\mathrm{T})=7$ give $\gamma \sim 1.45$ and $B=32.59$; and $E(T)=10$ and $S D(T)=10$ give $\gamma-1.00$ and $B=10$. Note the large $B$ values that result. Such parameter values seem very unrealistic. 
Figures 13-15 are graphs of the Wejbull pdf, cdf, and failure rate furctioil for each of the five cases.

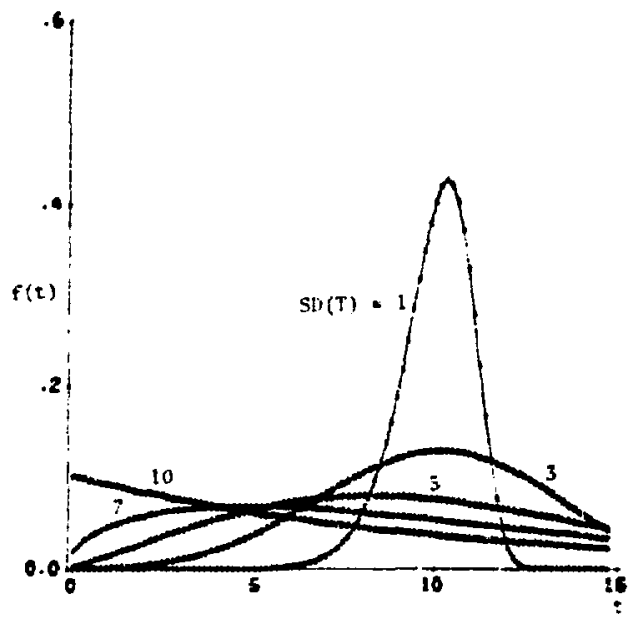

Fig. 13. The Weibull probability density function with $E(T)=10$ and $\mathrm{SD}(\mathrm{T})=1,3,5,7$, an: 10 .

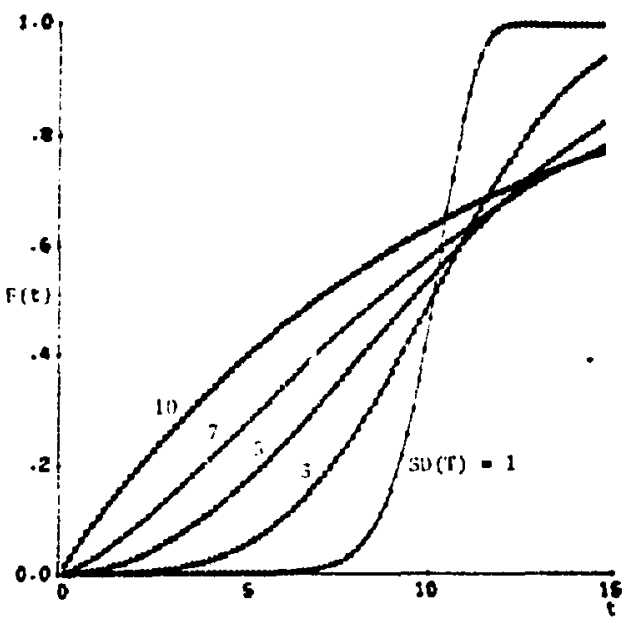

Fig. 14. The Weibul1 cumulative distributjon function with $E(T) \times 10$ and $\operatorname{SD}(T)=1,3,5,7$, and 10 .

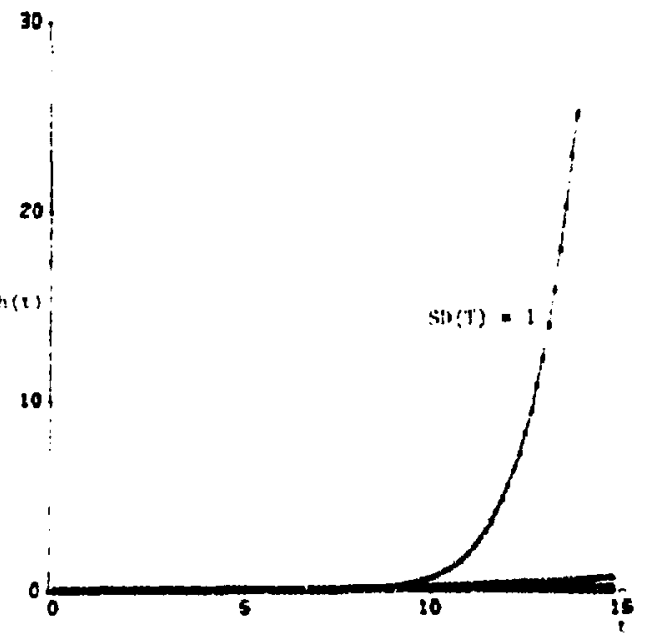

Fig. 15. The Weibull failure rate funceion with $I(T)$ o 10 and $S n(T)=1,3$, $5,-$ and 10 .

The probability of a failure within years is given hy

$$
\begin{aligned}
P(T \leq t) & =\int_{0}^{t} \gamma / \beta x^{i-1} \exp \left(-x^{\gamma} / \beta\right) d x \\
& =1-\exp \left(-t^{\gamma} / \beta\right) .
\end{aligned}
$$

The results are shown in Tables II - I']

2.6. Summary: The Probability of a Failure in the Heart System

For the exponential distribution, the probability of a failure in the heart system is high during the initial years, reaches 0.5 before the seventh year instead of the tenth year, and does not exceed 0.8 even during the fifteenth year.

The results for the other distributions considered (see Tables II-VI) show simiiar probabilities within tables. In a comparison among tables, the probabilities of a failure during the first 10 years generally increase as the standard deviations increase, then after the tenth year the probabilities generally decrease as the standard deviations increase. 


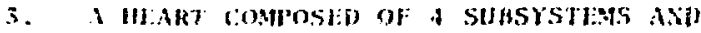
19 contosists

lha four subststeth of the artificial heart are a therata! comerter, a blood pump. Ilexible shafe assembly, and a cool. Lat: sysect. It will the assumed that they ale connerted in serics; that is, failuro of any one suhsytem irmbies failure of the entire heart sysem, where each subiystem aperafes independently of the others ippentix ij.

\subsection{The mponent ial iniluge listribut inn}

Fitst, consider the case in which each :ubsyelem bas an coxponential fallure distri. tat ion with perancter t The probability of a fallure in the system nithin thars i :s

$$
\begin{aligned}
& \text { l }\left(T_{s} \div 1\right) \\
& \text { - Pat lajst one sibsystern fails before }
\end{aligned}
$$

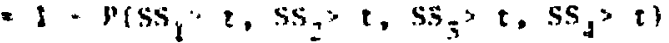

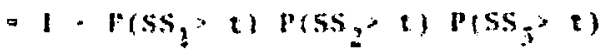

$$
\begin{aligned}
& \mathrm{PaSs}_{4} \text {;e) } \\
& =1 \cdot\left(0^{-(t / 2}\right)^{4}=1-e^{-4 t / 3}
\end{aligned}
$$

hileres refers to system and $S s_{n}$ refers to subsystem $n$. The result is an exponentinl distribution with parameter $h / 4$. The mean and variance of the random variable $T$ for the sytitem are

$$
1:\left(\tau_{S}\right)=x / 4=10 \Longrightarrow i=40
$$

and

$$
V\left(T_{S}\right)=1600
$$

Thus, if each subsystem has a mean life of $40 \mathrm{yr}$ and a variance of $1600 \mathrm{yr}$ (or a standard deviation of $40 \mathrm{yr}$ ), the heart system will have a mean life of $10 \mathrm{yr}$ and a variance of $100 \mathrm{yr}$ (or a standard deviation of $10 \mathrm{yr}$ ). From a practical standpoint, such large variances are undesirable. Moreover, a mean 1 ife of $40 \mathrm{yr}$ is not realistic.
To go one step further, assume that the four subsystems have $k_{1}, k_{2}, k_{3}$, and $k_{4}$ components, respectively. lach component has an exponential failure distribution with parameter $i$ and each operates independently. In reality, several different failure dis. ributions tat bo represented within a subsyitesn and failure of a single component thit not imply failure of the subsystem and. subsequently, of the entire heart system as the series connection suggests. Severtheless. for simplizity of calculation and illustration, these assumptions are made.

The probability of a failure in the heart is now given as

$f\left(t^{2} \div-t\right)$

- fa least one subiytem fajls before time $t$

$=1-P\left(S S_{1}>t, S S_{2}>t, S S_{3}>t, S S_{4}>t\right)$

- $\left.1-P\left(S s_{1}, t\right) P\left(S S_{2}\right) t\right) P\left(S S_{3}>t\right)$

$\left.p\left(s s_{4}\right) t\right)$

$=P\left(c_{11}>t, \ldots . c_{1 k_{1}}>t\right)$

$p\left(c_{21}>t, \ldots, c_{2 k}>t\right)$

$P\left(C_{31}>t, \ldots, C_{3 k_{5}}>t\right)$

$P\left(C_{41}>t, \ldots, C_{4 k_{4}}>t\right)$

- $1-P\left(C_{11}>t\right) \ldots P\left(C_{1 k_{1}}>t\right)$

$P\left(C_{21}>t\right) \ldots P\left(C_{2 k}>t\right)$

$P\left(C_{51}>t\right) \ldots F\left(C_{3 k_{5}}>t\right)$

$P\left(C_{41}>t\right) \ldots P\left(C_{4 k_{4}}>i\right)$

$=1-\left(e^{-t / \lambda}\right)^{k_{1}+k_{2}+k_{3}+k_{4}}$

$=1-e^{-\left(k_{1}+k_{2}+k_{3}+k_{4}\right) t / \lambda}$,

where $c_{i j}$ refers to component $j, j=1, \ldots$, $k_{i}$, in the ith subsystem. The result is an exponential distribution with parameter $\left.\frac{\lambda}{\left(k_{1}+k_{2}+k_{3}+k_{4}\right.}\right)$. Thus, each component 
should have a mean life of $\left(k_{1}+k_{2}+k_{3}+\right.$ $\mathrm{k}_{4}$ ) $\times 10 \mathrm{yr}$ for the heart to have a mean life of $10 y r$. As there are 99 components in the artificial heart, the requirement is an incredible mean life of $990 \mathrm{yr}$ each.

of those 99 components, 53 are in the first subsystem, 37 in the second, 5 in the third, and 4 in the fourth. If it is assumed that each component has the same exponential distribution, the mean life required of each subsystem with $k_{i}$ components is

$$
\frac{10 \sum_{i=1}^{4} k_{i}}{k_{i}}
$$

years. That is,

$p\left(\mathrm{~T}_{\mathrm{SS}} \leq \mathrm{t}\right)$

$=P$ (at least one component in subsystem $i$ fails before time $t$ )

$=1-P\left(c_{i 1}>t, \ldots, c_{i k_{i}}>t\right)$

$=1-p\left(c_{i 1}>t\right), \ldots, p\left(c_{i k_{i}}>t\right)$

$=1-\exp \left[-t /\left(10 \sum_{i=1}^{4} k_{i}\right)\right]^{k_{i}}$

$=1-\exp \left[-k_{i} t /\left(10 \sum_{i=1}^{4} k_{i}\right)\right]$.

This is an exponential distribution with

parameter $\frac{10 \sum_{i=1}^{4} k_{i}}{k_{i}}$. Thus, for the heart to have a mean life of $10 \mathrm{yr}$, each subsystem should have a mean life of $18.68,26.76,198.00$, and $247.50 \mathrm{yr}$, respectively. (The life values of subsystems and comporients are rounded to two decimal places throughout this report.) The latter values, especially, are probably impossible to achieve in practice. 3.2. The Normal Failure Distribution When each subsystem has a normal failure distribution with parameters $\mu$ and $\sigma^{2}$, the probability of a failure in the system within $t$ years is

$$
P\left(T_{S} \leq t\right)=1-\left(\int_{\frac{t-\mu}{\sigma}}^{\infty} \frac{1}{\sqrt{2 \pi}} e^{-z^{2} / 2} d z\right)^{4} .
$$

In determining the mean 1 ife required of each subsystem given $10-y r$ mean 1 ife of the heart, there is the problem that the above result is not normally distributed. In an attempt to solve the problem, additional constraints are imposed and a trial and error process is used. Given preassigned values for the standard deviation of $T_{S S}$, where the subscript SS refers to subsystem, the following values for the mean of ${ }^{\mathrm{T}} S S, j=E\left(\mathrm{~T}_{S S}\right)$, give $\mathrm{P}\left(\mathrm{T}_{S} \leq 10\right)=$ 0.5 . Note trat, by definition, the value of $t$ such that $P(T<t) \leq 0.5$ and $P(T \leq t) \geq$ 0.5 is called the median of the distribution of the random variable $T$. Hence, in satisfying the assumption that $P\left(T_{S} \leq 10\right)=$ 0.5 , DBER's objective of developing an artificial heart with a mean life of $10 \mathrm{yr}$ changes to that of developing a heart with a median life of $10 \mathrm{yr}$ (Appendix B). Notationa11y, $t_{M}$ denotes the median. For $\sigma=\mathrm{SD}\left(\mathrm{T}_{\mathrm{SS}}\right)=1, \mu=\mathrm{E}\left(\mathrm{T}_{\mathrm{SS}}\right)=11.00$; for $\sigma=3, \mu=12.99$; for $\sigma=5, \mu=14.99$; for $\sigma=7, \mu=16.99$; and for $\sigma=10$, $\mu=19.98$.

If the four subsystems have 99 components and all the components have the same normal failure distribution, a comparable trial and error process involving preassigned standard deviation values is used to determine the mean life values of the components indirectly. Again, it is assumed that the median life of the heart is $10 \mathrm{yr}$. The probability of a failure in the heart within $t$ years, given its composition of 99 components, is

$P\left(T_{S} \leq t\right)=1-\left[\int_{\frac{t-\mu}{\sigma}}^{\infty} \frac{1}{\sqrt{2 \pi}} \exp \left(-z^{2} / 2\right) d z\right]^{99}$ 
For $t=10$ and $\sigma=\operatorname{SD}\left(T_{C}\right)=1,3,5,7$, and 10 where the subscript $c$ indicates components, this equation is set equal to 0.5 and solved for $\mu$. For these five cases, the results show that each of the 99 components should have a mean 1 ife, $\mu$, of $12.46,17.38$, $22.29,27.21$, sod $34.58 \mathrm{yr}$, respectively.

The median 1 ife required of each subsystem with $k_{i}$ components each of which has the same normal distribution is calculated us ing

$p\left(\mathrm{~T}_{\mathrm{SS}_{i}}-\mathrm{t}\right)=1-\left[\int_{\frac{\mathrm{t}-\mu}{\sigma}}^{\infty} \frac{1}{\sqrt{2 \pi}} \exp \left(-\mathrm{z}^{2} / 2\right) \mathrm{d} z\right]^{\mathrm{k} i}$.

For subsystem I, for example, solve for $t$ using

$$
\begin{aligned}
& P\left(\mathrm{~T}_{S S_{1}} \leq t\right) \\
&=1-\left[\int_{\frac{t-\mu}{\sigma}}^{\infty}-\frac{1}{\sqrt{2 \pi}} \exp \left(-z^{2} / 2\right) \mathrm{dz}\right]^{53}=0.5 .
\end{aligned}
$$

If each component has a mean 1 ife, $\mu$, of $12.46 \mathrm{yr}$ and a standard deviation, $\sigma$, of $1 \mathrm{yr}, \mathrm{P}\left(\mathrm{T}_{\mathrm{SS}_{1}} \leq 10.23\right)=0.5$. That is,

subsystem I has a median 1 ife of $10.23 \mathrm{yr}$. Results of using the other previously given values for the mean and standard deviation of the components of each of the four subsystems are shown in Table VII. Still another approach may be taken. If each subsystem is required to have the same normal distribution, specifically, the same median life, then the mean life of each component in a particular subsystem can be calculated using

$$
\begin{aligned}
& F\left(\mathrm{~T}_{\mathrm{SS}_{\mathrm{i}}} \leq \mathrm{t}\right) \\
& =1-\left[\int_{\frac{\mathrm{t}-\mathrm{H}}{\sigma}}^{\frac{1}{\sqrt{2 \pi}}} \exp \left(-\mathrm{z}^{2} / 2\right) \mathrm{dz}\right]^{\mathrm{k}_{\mathrm{i}}}=0.5 .
\end{aligned}
$$

To illustrate, for subsystem $I$, setting $\sigma=S D\left(T_{C}\right)=1$ and using the previously calculated value $E\left(T_{S S}\right)=11.00=t$ gives

$$
\begin{aligned}
P\left(\mathrm{~T}_{\mathrm{SS}} \leq\right. & \leq 11.00) \\
& =1-\left[\int_{\frac{11.00 \cdot \mu}{1}}^{\infty} \frac{1}{\sqrt{2 \pi}} \exp \left(-z^{2} / 2\right) \mathrm{dz}\right]^{53}
\end{aligned}
$$$$
=0.5 \text {. }
$$

Trial and error give $\mu=E\left(T_{c}\right)=13.23$. Similar calculations for other values of $S D\left(T_{c}\right)$ and $E\left(T_{S S}\right)$ for each of the four subsystems are summarized in Table VIII. 3.3 The Lognormal Failure Distribution

If each subsystem has a lognormal failure distribution with parameters $\mu$ and $\sigma^{2}$, the probability of a failure in the heart within $t$ years is

$$
\begin{aligned}
& P\left(T_{S} \leq t\right) \\
& =1-\left[\int_{\frac{\log _{e} t-\mu}{\sigma}}^{\infty} \frac{1}{\sqrt{2 \pi}} \exp \left(-z^{2} / 2\right) \mathrm{d} z\right]^{4} .
\end{aligned}
$$


and $\operatorname{SD}\left(\mathrm{X}_{\mathrm{SS}}\right)-0.29$; for $\mathrm{SD}\left(\mathrm{T}_{\mathrm{SS}}\right)=5, \mathrm{E}\left(\mathrm{T}_{\mathrm{SS}}\right)=$ $17.92, E\left(X_{S S}\right) \sim 2.77$, and $S D\left(X_{S S}\right) \sim 0.47$.

Similarly, for $\operatorname{SD}\left(\mathrm{T}_{S S}\right)=7, \mathrm{E}\left(\mathrm{T}_{\mathrm{SS}}\right)=22.93$, $E\left(X_{S S}\right) \sim 2.93$, and $S D\left(X_{S S}\right)-0.63$; for $\mathrm{S})\left(\mathrm{T}_{S S}\right)=10, E\left(\mathrm{~T}_{S S}\right)=32.47, E\left(X_{S S}\right) \sim$

3.13 , and $\sin \left(x_{S S}\right) \sim 0.83$.

For the heart wit: 99 components each having the same lognormal distribution, the prohability of a failure in the system within $t$ years is

$\mathrm{P}(\mathrm{T} s \leq \mathrm{t})$

$=1-\left[\int_{\frac{\log _{c} t-\mu}{J}}^{\infty} \frac{1}{\sqrt{2 \pi}} \exp \left(-z^{2} / 2\right) d z\right]^{99}$.

Given $t=10, P\left(T_{S} \leq 10\right)=0.5$, and $\sigma=\operatorname{SD}\left(\mathrm{T}_{\mathrm{c}}\right)=1,3,5,7$, and 10 , each of

the 99 components should have a mean life, $\mu$, of $12.84,21.49,35.71,57.65$, and $109.50 \mathrm{yr}$, respectively, for the system to have a median life of $10 \mathrm{yr}$. If $X_{c}=\log _{e} T_{c}$ is normally distributed, $E\left(X_{c}\right) \sim 2.55,3.02,3.46,3.86$, and 4.35 for the five cases, and $\operatorname{SD}\left(X_{c}\right) \sim 0.10$, $0.29,0.47,0.63$, and 0.83 .

In considering the distribution of the components among the four subsystems, use $P\left(\mathrm{~T}_{\mathrm{SS}_{i}} \leq t\right)$

$=1-\left[\int_{\frac{\log _{e} t-\mu}{\sigma}}^{\infty} \frac{1}{\sqrt{2 \pi}} \exp \left(-z^{2} / 2\right) d z\right]^{k_{i}}$

where each component is assumed to have the same lognormal distribution. With this equation set equal to 0.5 , the median 1 ife required of each subsystem is obtained by solving for $t$ using the values of $\mu=E\left(T_{C}\right)$ and $\sigma=S D\left(T_{c}\right)$ calculated in the previous paragraph. Results are shown in Table IX.
If each subsystem has the same lognormal distribution (the same median life), the mean 1 ife required of each component within a particular subsystem is obtained by solving for $\mu$ using the previously calculated values for $\sigma$ and $t$ in

$$
\mathrm{P}\left(\mathrm{T}_{\mathrm{SS}} \leq \mathrm{t}\right)
$$

$$
\begin{aligned}
& =1-\left[\int_{\frac{\log _{e} t-\mu}{\sqrt{2 \pi}}}^{\infty} \exp \left(-z^{2} / 2\right) d z\right]^{k_{i}} \\
& =0.5 \text {. }
\end{aligned}
$$

These calculations are given in Table $x$. 3.4. The Gamma Failure Distribution

When each subsystem has a gamma failure distribution with parameters $x$ and $B$, the probability of a failure in the system within $t$ years is

$$
\begin{aligned}
& P\left(T_{S} \leq t\right) \\
& =1-(1-\Phi)\left[\left(\frac{t}{\alpha \beta}\right)^{1 / 3}-1\right. \\
& \left.\left.+\frac{1}{9 \alpha}\right] 3 \sqrt{\alpha} \mid\right)^{4},
\end{aligned}
$$

again by use of the Wilson-Hilferty approximation. The result is not a gamma distribution. Trial and error are used to find the mean life required of each subsystem if the median life of the system is to be $10 \mathrm{yr}$. For $P\left(T_{S} \leq 10\right)=0.5$, $\mathrm{SD}\left(\mathrm{T}_{\mathrm{SS}}\right)=1$, say, implies that $E\left(\mathrm{~T}_{\mathrm{SS}}\right)=$ $11.00, \alpha \sim 120.93$, and $\beta \sim 0.09$. Likewise, $\mathrm{SD}\left(\mathrm{T}_{\mathrm{SS}}\right)=3$ gives $\mathrm{E}\left(\mathrm{T}_{\mathrm{SS}}\right)=12.97, \alpha \sim 18.68$, and $\beta \sim 0.69 ; \mathrm{SD}\left(\mathrm{T}_{S S}\right)=5$ gives $E\left(\mathrm{~T}_{S S}\right)=$ $14.89, \alpha \sim 8.87$, and $\beta \sim 1.68 ; \operatorname{SD}\left(\mathrm{T}_{\mathrm{SS}}\right)=$ 7 gives $E\left(T_{S S}\right)=16.77, \alpha \sim 5.74$, and $\beta \sim 2.92$; and $\operatorname{SD}\left(\mathrm{T}_{S S}\right)=10$ gives $\mathrm{E}\left(\mathrm{T}_{\mathrm{SS}}\right)=$ $19.51, \alpha \sim 3.81$, and $\beta \sim 5.13$. 
Given the 99 components each of which has the same gamma distribution, the probability of a failure in the heart within $t$ years is

$$
\begin{aligned}
& P\left(T_{S} \leq t\right) \\
& =1-\left(1-\frac{1}{(1}\left[\left(\frac{t}{\alpha \beta}\right)^{1 / 3}-1\right.\right. \\
& \left.\left.\left.+\frac{1}{9 \alpha}\right] 3 \sqrt{\alpha}\right)\right)^{99} .
\end{aligned}
$$

For $t=10, P\left(T_{S} \leq 10\right)=0.5$ and $\operatorname{SD}\left(T_{c}\right)=1$, $3,5,7$, and 10 , the mean 1 ife required of each component is $12.32,16.46,20.23$, 23.78 , and $28.84 \mathrm{yr}$, respectively. In these five cases, the $\alpha$ values are $\alpha-151.83,30.10,16.37,11.54$, and 8.32 and the $B$ values are $B \sim 0.08,0.55,1.24$, 2.06 , and 3.47 .

To calculate the median 1 ife required of each subsystem with $k_{i}$ components, set

$$
\begin{aligned}
& P\left(T_{S S_{i}} \leq t\right) \\
& =1-(1-\Phi)\left[\left(\frac{t}{\alpha B}\right)^{1 / 3}-1\right. \\
& \left.\left.\left.\quad+\frac{1}{9 \alpha}\right] 3 \sqrt{\alpha}\right)\right)^{k_{i}}=0.5
\end{aligned}
$$

and solve for $t$ using the $a$ and $f$ values obtained for $E\left(T_{c}\right)$ and $S D\left(T_{c}\right)$ in the previous paragraph. These results are shown in Table XI.

If each subsystem has the same gamma distribution (the same median life), solving

$$
\begin{aligned}
& P\left(T_{S S_{i}} \leq t\right) \\
& =1-(1-\bar{\omega})\left[\left(\frac{t}{\alpha \beta}\right)^{1 / 3}-1\right. \\
& \left.\left.\left.+\frac{1}{9 \alpha}\right] 3 \sqrt{\alpha}\right\}\right)^{k_{i}}=0.5
\end{aligned}
$$

for $\alpha \beta=E\left(T_{c}\right)$ using the previous $1 y$ calculated values of $t$ gives the mean 1 ife required of each component within a subsystem. These results, as well as the values for $\mathrm{SD}\left(\mathrm{T}_{\mathrm{c}}\right), \alpha$, and $B$, are gjven in Table XII. 3.5. The Weibull Failure Distribution

If each subsystem has a Weibull failure distribution with parameters $\gamma$ and $B$, the probability of a failure in the system within $t$ years is

$$
\mathrm{F}\left(\mathrm{T}_{S} \leq \mathrm{t}\right)=1-\exp \left(-\frac{t^{\gamma}}{\beta}\right)^{4},
$$

which is a Weibull distribution with parameters $\gamma$ and $B / 4$. Assuming that the mean 1 ife of the heart system is $10 \mathrm{yr}$ and the standard deviation is $1 \mathrm{yr}$, if $\gamma-12.92$ and $B \sim 5.78 \times 10^{13}$, the mear. 1 ife and standard deviation required of each subsystem are 11.16 and 1.05 , respectively. Similarly, for $S D\left(T_{S}\right)=3, \gamma \sim 3.70$ and $B \sim 2.89 \times 10^{4}$ imply that $E\left(T_{S S}\right)=14.50$ and $S D\left(T_{S S}\right)=4.37$. For $S D\left(T_{S}\right)=5$, $\gamma=2.10$ and $\beta=6.48 \times 10^{2}$ imply that $E\left(T_{S S}\right)=19.34$ and $\operatorname{SD}\left(T_{S S}\right)=9.68$, and for $\operatorname{SD}\left(\mathrm{T}_{\mathrm{S}}\right)=7, \gamma-1.45$ and $B-1.30 \times 10^{2}$ imply that $E\left(T_{S S}\right)=25.99$ and $S D\left(T_{S S}\right)=$ 18.19. If $\operatorname{SD}\left(\mathrm{T}_{S}\right)=30, \gamma \sim 1.00$ and $B \sim 40.00$ give $E\left(T_{S S}\right)=40.00$ and $S D\left(T_{S S}\right)=40.00$.

For a heart with 99 components, each having the same Weibull distribution, the probability of a failure within $t$ years is

$$
P\left(T_{S} \leq t\right)=1-\exp \left(-\frac{t^{\gamma}}{B}\right)^{99},
$$

which is a Weibull distribution with parameters $\gamma$ and $B / 99$. A mean life of $10 \mathrm{yr}$ and a standard deviation of $1,3,5,7$, and 10 yr for the heart system were the conditions placed on the following calculations. For $\gamma \sim 12.05$ and $e \sim 1.84 \times 10^{14}$, the mean 1 ife and standard deviation of each component are $14.64 \mathrm{yr}$ and $1.48 \mathrm{yr}$, respectively. For $\operatorname{SD}\left(T_{S S}\right)=3, \gamma \sim 3.70$ and $\beta \sim 7.14 \times 10^{5}$ imply that $E\left(T_{c}\right)=34.54$ and $\operatorname{SD}\left(T_{c}\right)=10.40$. 
Similarly, for $S D\left(T_{S S}\right)=5, \gamma \sim 2.10$, $\beta \sim 1.60 \times 10^{5}, E\left(T_{C}\right)=89.20$, and $\operatorname{SD}\left(T_{C}\right)=44.65$. For $\operatorname{SD}\left(T_{S S}\right)=7, \gamma \sim 1.47$, B. $3.39 \times 10^{4}, E\left(T_{c}\right)=231.98$, and $\operatorname{SD}\left(T_{c}\right)=$ 160.89. For $S D\left(T_{S S}\right)=10, \gamma-1.01$, $\beta=1.02 \times 10^{3}, E\left(T_{C}\right)=966.00$, and $\operatorname{SD}\left(T_{C}\right)=$ 959.41 .

For a subsystem with $k_{i}$ components each of which has the same Weibull distribution, the probability of a failure in the subsystem within $t$ years is

$$
P\left(T_{S S_{i}} \leq t\right)=1-\exp \left(-\frac{t^{\gamma}}{\beta}\right)^{k_{i}}
$$

which is a Weibul1 distribution with parameters $\gamma$ and $B / k_{i}$. Given the values for $E\left(T_{S S}\right)$ and $S D\left(T_{S S}\right)$ obtained previously, the mean life, standard deviation, $\alpha$, and $\beta$ values required of each component within a subsystem, assuming an identical Weibull failure distribution for each subsystem, are as shown in Table XIII.

\subsection{Summary: The Life Requirements of a}

\section{Subsystem with $k$ Components}

In comparing the mean life or median Iife of a subsystem or component as calculated for the various probability distributions, it appears that stringent assumptions and requirements are sometimes needed.

The means and standard deviations of the exponential and Weibull distributions are extremely high. The results for the other three distributions, in similar preassigned standard deviation condition;, show comparable mean life values for the three subsystems. As for the mean life values of the 99 components, the lowest requirements came from using the gamma distribution, whereas the highest came from using the Weibull distribution.

Assuming that each component of the heart system has the same failure distribution gives median life values of each subsystem with $k$ components derived using a normal distribution, a lognormal distribution, and a gamna distribution which are very similar to each other. Note that the median life required of a subsystem with fewer components is a few years longer than that of a subsystem with more components; i.e., the fewer the components, the less likelihood of a failure in the system, so the longer the median life. Just the opposite is true if each subsystem is assumed to have the same failure distribution, in particular, the same median life. Then, the fewer the components in the subsystem, the shorter the mean 1 ife required of each component.

It is recommended that experimental data obtained by testing the heart system be used to suggest failure distributions and parameter values of practical interest in calculating the probability of a failure within $t$ years and the mean or median life required of a particular subsystem or component. Although these computations will be more difficult, the results will be more realistic.

\section{RFFERENCES}

1. "The Evaluation of Practicability of a Radioisotope Thermal Converter for an Artificial Heart Device, Phase II Final Report," Westinghouse Astronuclear Laboratory, Pittsburgh, Pennsylvania, Report COD-3043-10, (1973).

2. William L, Hays, Statistics (Holt, Rinehart and Winston, Inc., New York, 1963).

3. Norman L. Johrison and Samuel Kotz, Continuous Univariate Distributions 1 
APPENDIX $\wedge$

SYSTEM RELIABILITY

Because the heart is assumed to be a simple series system of components,

$$
R_{S}=R_{1}, R_{2}, \ldots, R_{n} \text {, }
$$

where $R_{S}$ is the system reliability and $R_{n}$ is the reliability of the individual components. Given the apportioned reliability of the components as shown in Table 5.4 of Ref. 1, the reliability of the system is 0.500636 . Of the 99 heart components, 22 have a reliability of $0.999999,70$ have a reliability of 0.999 , and 7 have a reliability of 0.915 . If these 7 components had a reliability of 0.999 instead of 0.915 , the reliability of the system would be 0.925854 . To speculate further, if each component had a reliability of $0.9999,0.99999$, and 0.999999 , respectively, the corresponding system reliabilities would be $0.990148,0.999010$, and 0.999901 .

APPENIIX B

THE MEAN VS THE MEDIAN

Two measures of a distribution's central tendency are the mean and the median. The mean is the long-term average of a random variable, and the median is the point below which $50 \%$ of the distribution lies. Although the median is mathematically less tractable, it is useful in descriptive statistics because it represents the typical score. The mean, nn the other hand, is useful when making inferences beyond the sample. 2

If the distribution is symmetrical, the mean and median are equal. If the distribution is asymmetrical or skewed, they usually are unequal. If a distribution is skewed to the right, or positively, the mean is usually larger than the median. If a distribution is skewed to the left, or negatively, the median is usually larger than the mean.

Note that the mean is very sensitive to changes in data scores at the extremes of a distribution, whereas such changes do not affect the median as long as the rank order of the scores is preserved. 
TABLE I

THE PROBABILITY OF A FAILURE IN THE HEART SYSTIBN FOR $t$ YEIRS ASSUMING A MEAN LIFE OF 10 YEARS, A VARIANCI: OF 100 YI:ARS, AND THE EXPONENTIAL FAILURI: DISTRIBUTION

\begin{tabular}{c} 
Years \\
\hline 1 \\
2 \\
3 \\
4 \\
5 \\
6 \\
7 \\
8 \\
9 \\
10 \\
11 \\
12 \\
13 \\
14 \\
15
\end{tabular}

\begin{tabular}{c} 
Fxponential \\
\hline 0.0952 \\
0.1813 \\
0.2592 \\
0.3297 \\
0.3935 \\
0.4512 \\
0.5034 \\
0.5507 \\
0.5934 \\
0.6321 \\
0.6671 \\
0.6988 \\
0.7275 \\
0.7534 \\
0.7769
\end{tabular}

TABLE II

THE PROBABILITY OF A FAILURE IN THE HEART SYSTEM FOR $t$ YEARS ASSUMING A MEAN LIFE OF 10 YEARS, A STANDARD DEVIATION OF

1 YEAR, AND VARIOUS FAİLUR DISTRIBUTIONS

Years IDistribution

1

2

3

4

5

6

7

8

9

10

11

12

13

14

15
Norma1

0.0000

0.0000

0.0000

0.0000

0.0000

0.0000

0.0013

0.0228

0.1587

0.5000

0.8413

0.9772

0.9987

1.0000

1.0000

\begin{tabular}{l} 
Lognormal \\
\hline 0.0000 \\
0.0000 \\
0.0000 \\
0.0000 \\
0.0000 \\
0.0000 \\
0.0002 \\
0.0144 \\
0.1571 \\
0.5199 \\
0.8426 \\
0.9698 \\
0.9963 \\
0.9997 \\
1.0000
\end{tabular}

$\frac{\text { Lognorma 1 }}{0.0000}$

Gamma

0.0000

0.0000

0.0000

0.0000

0.0000

0.0000

0.0004

0.0171

0.1582

0.5133

0.8418

0.9721

0.9972

c. 9998

1.0000
Weibull

0.0000

0.0000

0.0000

0.0000

0.0001

0.0012

0.0078

0.0390

0.1534

0.4508

0.8517

0.9959

I. 0000

1.0000

1.0000 
TABLE III

THE PROBABILITY OF A FAILURE IN THE HEART SYSTEM FOR $t$ YEARS ASSUMING A MEAN LIFE OF 10 YBARS, A STANDARD DEVIATION OF:

3 YEARS, AND VARIOUS FAILURE DISTRIBUTIONS

\begin{tabular}{ccccc} 
YearsiDistribution & $\frac{\text { Normal }}{0.0013}$ & $\frac{\text { Lognormal }}{0.0000}$ & Gamma & $\frac{\text { Weibull }}{0.0001}$ \\
\hline 1 & 0.0038 & 0.0000 & 0.0000 & 0.0017 \\
3 & 0.0098 & 0.0000 & 0.0007 & 0.0078 \\
4 & 0.0228 & 0.0015 & 0.0057 & 0.0225 \\
5 & 0.0478 & 0.0134 & 0.0248 & 0.0508 \\
6 & 0.0912 & 0.0555 & 0.0714 & 0.0975 \\
7 & 0.1587 & 0.1427 & 0.1536 & 0.1662 \\
8 & 0.2525 & 0.2698 & 0.2687 & 0.2580 \\
9 & 0.3694 & 0.4160 & 0.4032 & 0.3701 \\
10 & 0.5000 & 0.5583 & 0.5398 & 0.4952 \\
11 & 0.6306 & 0.6813 & 0.6638 & 0.6224 \\
12 & 0.7475 & 0.7787 & 0.7663 & 0.7396 \\
13 & 0.8413 & 0.8509 & 0.8447 & 0.8365 \\
14 & 0.9088 & 0.9020 & 0.9009 & 0.9079 \\
15 & 0.9522 & 0.9367 & 0.9391 & 0.9541
\end{tabular}

TABLE IV

THE PROBABILITY OF A FAILURE IN THE HEARI SYSTEM FOR $t$ YEARS ASSUMING A MEAN LIFE OF 10 YEARS, A STANDARD JEVIATION OF 5 YEARS, AND VARIOUS FAILURE DISTRIBUTIONS

\section{Years\Distribution}

1

2

3

4

5

6

7

8

9

10

11

12

13

14

15
Norma 1

0.0359

0.0548

0.0808

0.1151

0.1587

0.2119

0.2743

0.3446

0.4207

0.500 )

0.5793

0.6554

0.7257

0.7881

0.8413
Lognormal

$$
0.0000
$$

0.0008

0.0104

0.0442

0.1091

0.1990

0.3019

0.4066

0.5052

0.5934

0.6693

0.733 J

0.7557

0.8286

0.8631
Gamma

0.0012

0.0100

0.0346

0.0789

0.1421

0.2198

0.3065

0.3961

0.4339

0.5662

0.6407

0.7063

0.7627

0.8102

0.8497
We1bull

0.0061

0.0260

0.0599

c. 1068

0.1652

5. 2327

0.3066

0.3842

0.4626

0.5392

0.6120

0.6791

0.7394

0.7922

0.8374 
THF PROBABILITY OF A FAILURE IN THE HEART SYSTEN FOR $t$ YEARS ASSUMING A MEAN LIFE OF 10 YEARS, A STANDARD DEVIATION OF

7 YEARS, AND VARIOUS FAILURE DISTRIBUTIONS

\begin{tabular}{ccccc} 
Years Distribution & Norma1 & Lognjrma1 & Gamma & Weibu11 \\
\hline 1 & 0.0993 & 0.0004 & 0.0196 & 0.0302 \\
2 & 0.1265 & 0.0128 & 0.0610 & 0.0805 \\
3 & 0.1587 & 0.0558 & 0.1183 & 0.1403 \\
4 & 0.1957 & 0.1281 & 0.1855 & 0.2050 \\
5 & 0.2375 & 0.2171 & 0.2576 & 0.2718 \\
6 & 0.2839 & 0.3109 & 0.3308 & 0.3385 \\
7 & 0.3341 & 0.4017 & 0.4024 & 0.4036 \\
8 & 0.3875 & 0.4850 & 0.4706 & 0.4660 \\
9 & 0.4432 & 0.5592 & 0.5340 & 0.5250 \\
10 & 0.5000 & 0.6239 & 0.5922 & 0.5799 \\
11 & 0.5568 & 0.6796 & 0.6449 & 0.6307 \\
12 & 0.6125 & 0.7272 & 0.6921 & 0.6770 \\
13 & 0.6659 & 0.7677 & 0.7340 & 0.7190 \\
14 & 0.7161 & 0.8019 & 0.7710 & 0.7567 \\
15 & 0.7625 & 0.8309 & 0.8033 & 0.7903
\end{tabular}

TABLE VI

THE PROBABILITY OF A FAILURE IN THE HEART SYSTEM FOR 2 YEARS ASSUMING A MEAN LIFE OF 10 YEARS, A STANDARD DEVIATION OF 10 YEARS, AND VRIOUS FAILURE DISTRIBUTIONS

\begin{tabular}{ccccc} 
Years\Distribution & Normal & Lognormal & Gamma & $\frac{\text { Feibull }}{0.0952}$ \\
\hline 1 & 0.1841 & 0.0094 & 0.1013 & 0.095 \\
2 & 0.2119 & 0.0647 & 0.1808 & 0.1813 \\
3 & 0.2420 & 0.1515 & 0.2552 & 0.2592 \\
4 & 0.2743 & 0.2469 & 0.3241 & 0.3297 \\
5 & 0.3085 & 0.3386 & 0.3876 & 0.3935 \\
6 & 0.3446 & 0.4218 & 0.4458 & 0.4512 \\
7 & 0.3821 & 0.4952 & 0.4988 & 0.5034 \\
8 & 0.4207 & 0.5589 & 0.5471 & 0.5507 \\
9 & 0.4602 & 0.6140 & 0.5909 & 0.5934 \\
10 & 0.5000 & 0.6614 & 0.6306 & 0.6321 \\
11 & 0.5398 & 0.7022 & 0.6665 & 0.6671 \\
12 & 0.5793 & 0.7374 & 0.6989 & 0.6988 \\
13 & 0.6179 & 0.7677 & 0.7282 & 0.7275 \\
14 & 0.6554 & 0.7940 & 0.7547 & 0.7534 \\
15 & 0.6915 & 0.8168 & 0.7786 & 0.7769
\end{tabular}




\section{TABLE VII}

THE MEDIAN LIFE, $t_{M}$, REQUIRED OF EACH SUBSYSTEM WITH $k_{1}$ COMPONENTS ASSUMING AN IDENTICAL NORMAL FAILURE DISTRIBUTION FOR EACH COMPONENT

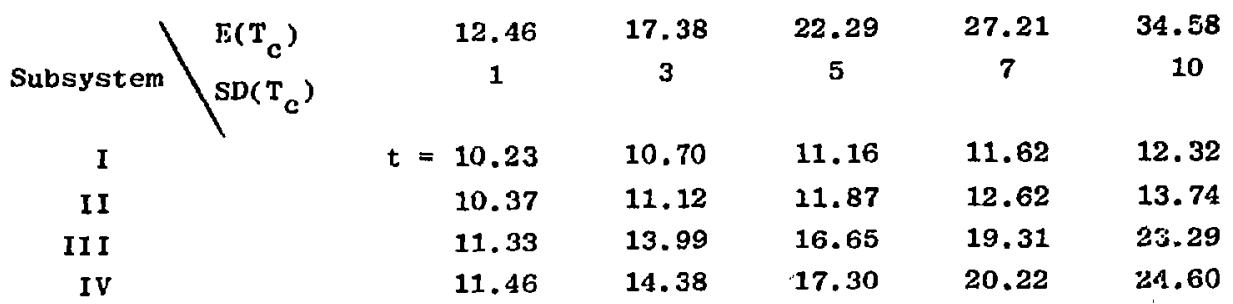

TABLE VIII

THE MEAN LIFE, $\mu$, REQUIRED OF EACH COMPONENT WITHIN A SUBSYSTEM ASSUMING AN IDENTICAL WORMAL FAILURE DISTRIBUTION FOR EACH SUBSYSTEM

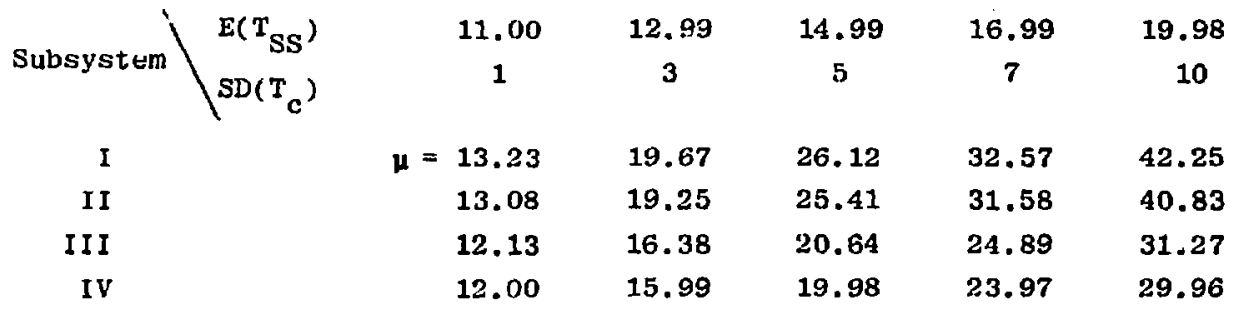

TABLE IX

THE MEDIAN LIFE, $t_{M}$, REQUIRED OF EACH SUBSYSTEM WITH $k_{1}$ COMPONENTS ASSUMING AN IDENTICAL LOGNORMAL FAILURE DISTRIBUTION FOR EACH COMPONENT

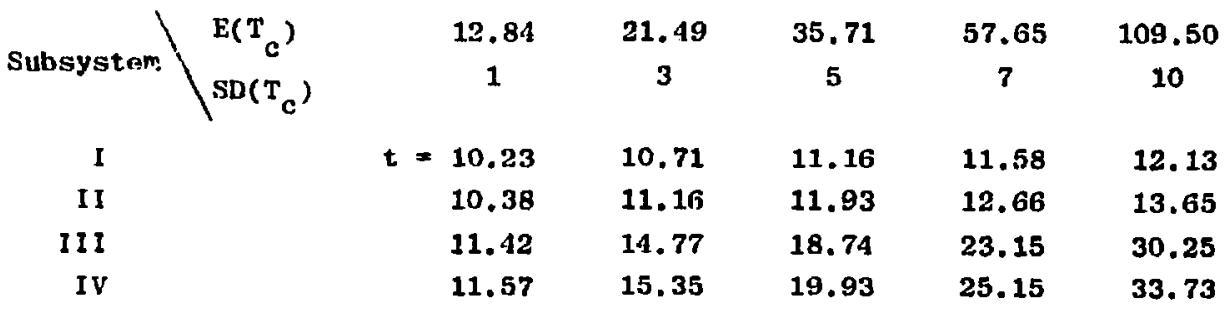


TABLE $X$

THE IEAN LIFE, $\mu$, REQUTRED OF EACH CONPONENT WITHIN A SUBSYSTEM ASSUMING AN IDENTICAI LOGNORMAL FAILURE DISTRIBUTION FOR EACH GUBSYSTEM Subsystem $\left\{\begin{array}{l}E\left(T_{S S}\right) \\ S D\left(T_{c}\right)\end{array}\right.$

11. 10

1

14. 00

17.92

5

22.93

32.47

$$
\text { I }
$$

I I

I I I

IV

$$
\begin{array}{r}
\mu=13.86 \\
13.67 \\
12.43 \\
12.26
\end{array}
$$

26.90
25.81
19.49
18.76

51.28

47. 96

93.53

85.51

207.22

30.54

46.77

184.12

28. 71

43.06

83. 11

74.53

TABLE XI

THE MEDIAN LIFE, $t_{M}$, REQUIRED OF EACH SUBSYSTEM WITH $k_{1}$ COMPONENTS ASSUMING AN IDENTICAL GAMMA FAILURE DISTRIBUTION FOR EACH COMPONENT

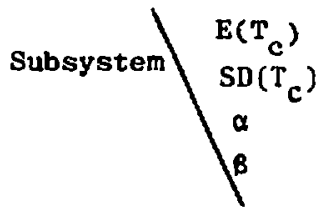

$\begin{array}{ccccc}12.32 & 16.46 & 20.23 & 23.78 & 28.84 \\ \cdot 1 & 3 & 5 & 7 & 10 \\ 151.83 & 30.10 & 16.37 & 11.54 & 8.32 \\ 0.08 & 0.55 & 1.24 & 2.06 & 3.47 \\ & & & & \\ t=10.20 & 10.51 & 10.74 & 10.94 & 11.19 \\ 10.32 & 10.83 & 11.22 & 11.54 & 11.96 \\ 11.20 & 13.14 & 14.76 & 16.19 & 18.10 \\ 11.33 & 13.48 & 15.29 & 16.90 & 19.08\end{array}$


THE IEAAN LIFE, STANDARD DEVIATION, $a$, AND B VALUES REQUIRED OF FACH COMPONENT WITHIN A SUBSYSTEM ASSUMING AN IDENTICAL GAMMA FAILURE DISTRIBUTION

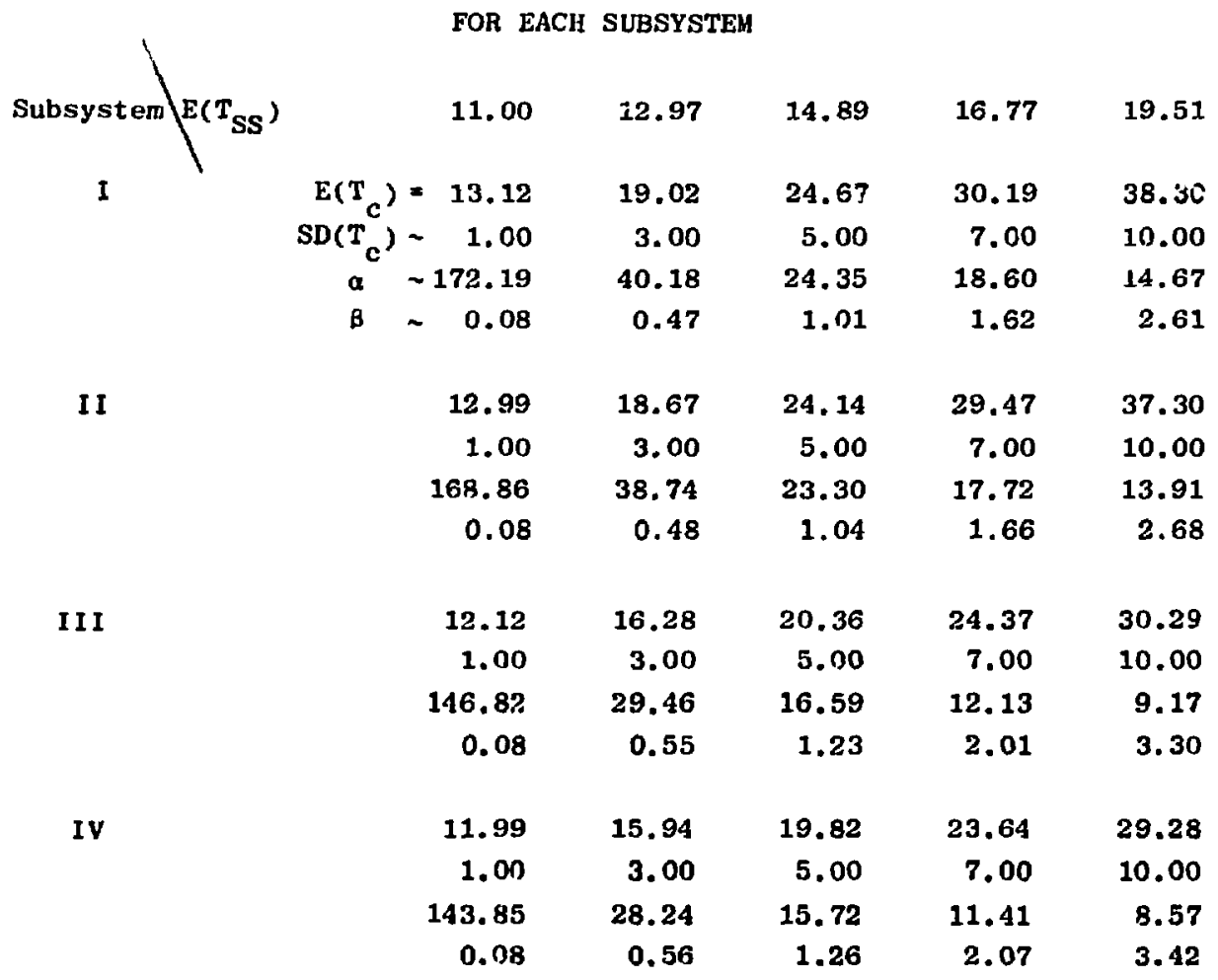


THE MEAN LIFE. STANDARD DEVIATION, $\alpha$, AND $\beta$ VALUES REOUIRED OF EACH COMPONENT WITHIN A SUBSYSTEM ASSUMING AN IDENTICAL WEIBULL.

FAILURE DISTRIBUTION FOR EACH SUBSYSTEM

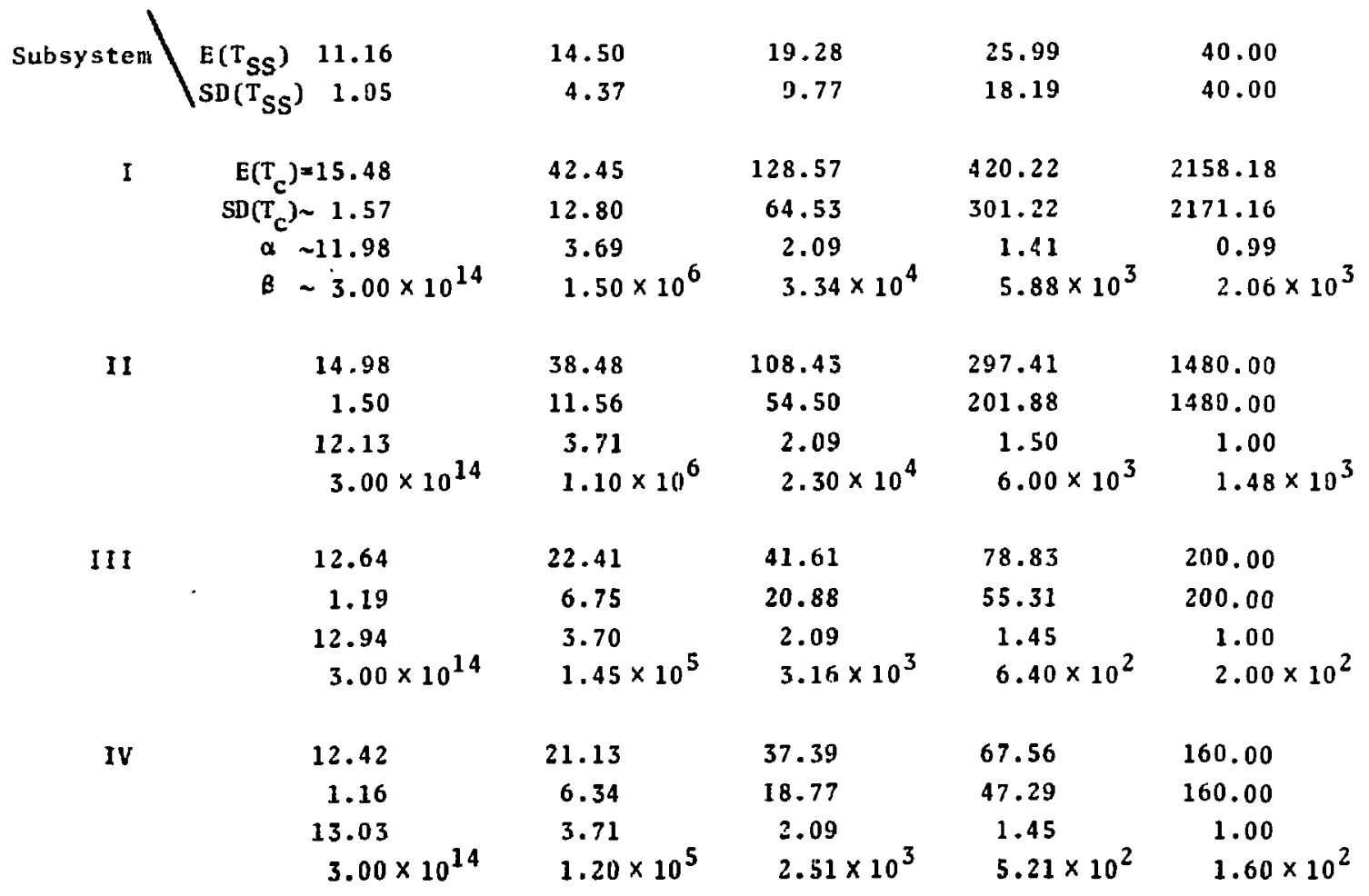

